\title{
Benzothiazine Dyes/2,4,6-Tris(trichloromethyl)-1,3,5-triazine as a New Visible Two-Component Photoinitiator System
}

\author{
Radosław Podsiadły, ${ }^{1}$ Radosław Michalski, ${ }^{2}$ Andrzej Marcinek, ${ }^{2}$ and Jolanta Sokołowska ${ }^{1}$ \\ ${ }^{1}$ Institute of Polymer and Dye Technology, Lodz University of Technology, Stefanowskiego 12/16, 90-924 Lodz, Poland \\ ${ }^{2}$ Institute of Applied Radiation Chemistry, Lodz University of Technology, Zeromskiego 116, 90-924 Lodz, Poland \\ Correspondence should be addressed to Radosław Podsiadły, radoslaw.podsiadly@p.lodz.pl
}

Received 7 May 2012; Accepted 7 September 2012

Academic Editor: Xie Quan

Copyright ( 92012 Radosław Podsiadły et al. This is an open access article distributed under the Creative Commons Attribution License, which permits unrestricted use, distribution, and reproduction in any medium, provided the original work is properly cited.

\begin{abstract}
Novel photoinitiator systems working under visible radiation were studied. The photoredox pair constructed with dye derivatives of 12H-quinoxalino-[2,3-b][1,4]-benzothiazine (1-3) and 2,4,6-tris(trichloromethyl)-1,3,5-triazine (Tz) were found to be effective initiators for free radical polymerization of trimethylolpropane triacrylate (TMPTA) using VIS light. Photosensitization occurred through electron transfer, which was confirmed by the observation of a radical cation of the studied dyes. The $\mathbf{1}^{\bullet+}$ was also characterized in cryogenic matrices (mixture of $\mathrm{CH}_{2} \mathrm{Cl}_{2}$ and ionic liquid: 1-butyl-3-methylimidazolium hexafluorophosphate $\left(\mathrm{BMIM}^{+} \mathrm{PF}_{6}{ }^{-}\right)$) and its reactivity was investigated by means of pulse radiolysis in solution at room temperature. In a halogenated solvent and in a mixture of $\mathrm{CH}_{2} \mathrm{Cl}_{2}$ and $\mathrm{BMIM}^{+} \mathrm{PF}_{6}{ }^{-}$, the radical cation $\mathbf{1}^{{ }^{++}}$underwent deprotonation to form a neutral radical $\mathbf{1}^{\bullet}$, which was stable in the second time scale. During photolysis of the $1 /$ Tz photoredox pair in 1-methyl-2-pyrrolidone and monomer, the formation of a neutral radical $\mathbf{1}^{\bullet}$ was not observed.
\end{abstract}

\section{Introduction}

One of the most widely used and simplest methods of polymer formation is radical chain addition polymerization. Light-induced photopolymerization has several advantages over other methods; the process occurs at low temperatures, and it can be controlled by manipulating the intensity and wavelength of irradiation. Photo-initiated free radical polymerization of multifunctional monomers produces highly crosslinked polymers with high thermal stability, mechanical strength, and resistance to solvent. These polymers have many industrial applications, specifically in coatings for flooring and furniture, dental restorative materials, optical fiber coatings, hard and soft contact lenses, and photolithography [1-3].

Compounds with an efficient absorbance at long wavelengths were the most significant photoinitiators in the past decade. Absorbance at lower energies is significant for two reasons: first, the development of efficient long-wavelength, UV and visible emitting light sources, such as lasers and LEDs for imaging, printing, and medical applications, has created an increasing demand for an initiator system that is effective in the 400 to $500 \mathrm{~nm}$ spectral region; secondly, in exterior durable photopolymers, the key development was photoinitiators that absorb outside of the UV absorption curve of traditional UV absorbers used to protect organic coatings from the harmful rays of the sun.

Many attempts have been made to develop efficient photoinitiating polymerization systems that can be used with visible light. Previously, two components systems that operated via photoinduced electron transfer were developed [320]. In such systems, dyes play an important role. Dyes are chromophores that absorb visible light and after excitation, they react with coinitiators (electron donor D or electron acceptor A) via electron transfer. In both cases, the initiating radicals are formed through the cleavage of the oxidized or reduced form of the coinitiator (Scheme 1).

In the photoreducible sensitization, the dye was photoreduced in the presence of a suitable reductant such as phenyltioacetic acid [8-10], N-phenylglycine $[9,10]$, amine [11-13], and alkyltriphenylborate salt $[14,15]$. 

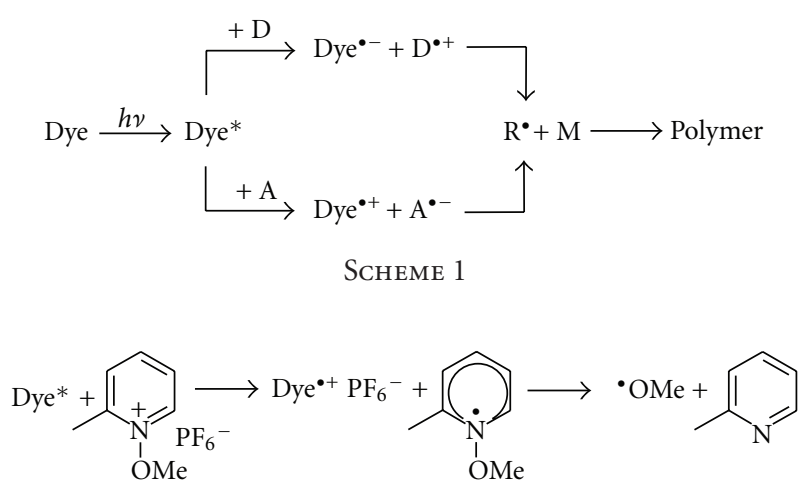

Scheme 2

In the last decade, dye/coinitiators systems working under visible irradiation via photooxidizable sensitization have been developed [3-7, 16-20]. In such photoredox pairs, $\mathrm{N}$-alkoxypyridinium salts were commonly used as coinitiators. Upon electron transfer, these compounds yielded alkoxy radicals (Scheme 2) which initiated polymerization. The second important coinitiator is the derivative of 2,4,6tris(trichloromethyl)-1,3,5-triazine. The halogenmethyl radicals formed are responsible for initiation of free radical polymerization (Scheme 3) [16-20].

It is well known in the literature that not all dyes are able to initiate photopolymerization with the aid of 2,4,6tris(trichloromethyl)-1,3,5-triazine (Tz) [16]. Therefore, the primary goal of the presented study is the application of dye derivatives of $12 \mathrm{H}$-quinoxalino-[2,3- $b][1,4]$-benzothiazine (1-3) in combination with $\mathrm{Tz}$ as a photoinitiator for free radical polymerization of a multifunctional acrylate (TMPTA). The structure of studied dyes and $\mathbf{T z}$ are presented in Scheme 4. Moreover, the photodarkening mechanism of dye 1 during photolysis was studied. The mechanism proposed is supported by spectroscopic characterization of its radical cation and neutral radical in low-temperature matrices (mixture of $\mathrm{CH}_{2} \mathrm{Cl}_{2}$ and ionic liquid: 1-butyl-3methylimidazolium hexafluorophosphate). The rigid environment of these matrices at cryogenic conditions on recombination and fragmentation processes allows for the direct observation of the transient species. This effect also allows for convenient observation of the undergoing processes upon a controlled annealing and softening of the rigid matrix environment.

\section{Experimental}

2.1. Generals. The procedure for preparing the dyes has been described elsewhere [7]. 2,4,6-tris(trichloromethyl)-1,3,5triazine (Tz) and 1-methyl-2-pyrrolidone (MP) were purchased from Wako-Chemicals and Sigma-Aldrich, respectively. Acetonitrile $(\mathrm{MeCN}), 2$-propanol (2-PrOH), dichloromethane $\left(\mathrm{CH}_{2} \mathrm{Cl}_{2}\right)$, and carbon tetrachloride $\left(\mathrm{CCl}_{4}\right)$ were purchased from POCH (Poland). The ionic liquid, 1-butyl3-methylimidazolium hexafluorophosphate $\left(\mathrm{BMIM}^{+} \mathrm{PF}_{6}{ }^{-}\right)$, was prepared by following the method of Huddleston et al. [21].
The absorption and steady state fluorescence spectra were recorded using a Jasco V-670 spectrophotometer and Jasco FP 6300 spectrofluorimeter (Jasco, Japan), respectively. All photochemical experiments were carried out in a Rayonet Reactor RPR 200 (The Southern New England Ultraviolet Co, USA) equipped with lamps emitting light at $419 \mathrm{~nm}$. A specific spectral band was isolated by the use of band-pass filters at $419 \pm 10 \mathrm{~nm}$. Illumination intensity was measured using uranyl oxalate actinometry [22].

2.2. Free Radical Polymerization. Free radical photopolymerization reactions were conducted in the presence of air in solvents composed of $1 \mathrm{~mL}$ of MP and $4 \mathrm{~mL}$ of TMPTA. Dye concentration was maintained at $0.1 \mathrm{mM}$, and the concentration of $\mathbf{T z}$ was $10 \mathrm{mM}$. The rate of polymerization $\left(R_{p}\right)$ was calculated from the following:

$$
R_{p}=Q_{s} \cdot \frac{M}{n \cdot \Delta H_{p} \cdot m} .
$$

In the above expression, $Q_{s}$ is a heat flow per second during the reaction, $m$ is the mass of the monomer in the sample, $M$ is the molar mass of the monomer, $n$ is the number of double bonds per monomer, and $\Delta H_{p}$ is the theoretical enthalpy for complete polymerization of acrylate double bonds $(20.6 \mathrm{kcal} / \mathrm{mol})$ [23]. The heat flow was measured with a PT 401 temperature sensor (Elmetron, Poland), immersed in the sample. A polymerizing mixture containing the dye without $\mathrm{Tz}$ was used as a reference sample.

2.3. Pulse Radiolysis. Pulse radiolysis experiments were carried out with high energy $(6 \mathrm{MeV}) 17 \mathrm{~ns}$ electron pulses generated from an ELU-6 linear electron accelerator. All measurements were performed at room temperature. The dose absorbed per pulse was determined with $\mathrm{N}_{2} \mathrm{O}$ saturated aqueous solution of $\operatorname{KSCN}(0.01 \mathrm{M})$, assuming $G\left((\mathrm{SCN})_{2}{ }^{--}\right)=6.2 \times 10^{-7} \mathrm{~mol} / \mathrm{J}$ and $\varepsilon\left((\mathrm{SCN})_{2}{ }^{\cdot-}\right)=$ $7600 \mathrm{M}^{-1} \mathrm{~cm}^{-1}$ ( $G$ represents the radiation chemical yield and $\varepsilon$ is a molar absorption coefficient at $475 \mathrm{~nm}$ ). The dose delivered per pulse was within the range of 5 to 80 Gy. Details of the pulse radiolysis system are provided elsewhere [24, 25].

2.4. Cryogenic Measurements. Glassy samples were prepared by quench-freezing room temperature solutions in liquid nitrogen. The samples were 1.5 to $2 \mathrm{~mm}$ thick and were placed in a temperature-controlled liquid nitrogen-cooled cryostat (Oxford Instruments-OptiStat DN). The desired temperature $(77$ to $150 \mathrm{~K}$ ) of the matrix was attained by automatically controlled heating. The samples mounted in a cryostat were irradiated with $4 \mu$ s electron pulses from the ELU-6 linear accelerator.

Radiolysis of the glassy sample of $\mathrm{BMIM}^{+} \mathrm{PF}_{6}{ }^{-}$and $\mathrm{CH}_{2} \mathrm{Cl}_{2}$ led to the production of solvated electrons and oxidizing holes represented by radical dication $\mathrm{BMIM}^{2+}$ and $\mathrm{PF}_{6}{ }^{\circ}$ (reaction (2)) or radical cation $\mathrm{CH}_{2} \mathrm{Cl}_{2}{ }^{\bullet+}$ (reaction (3)). The addition of methylene chloride to the matrix improved the solubility of many precursors but also resulted in more effective scavenging of electrons by dissociative electron attachment (reaction (4)) and led to a higher yield 
<smiles>[R]c1nc(C(Cl)(Cl)Cl)nc(C(Cl)(Cl)Cl)n1</smiles>

SCHEME 3<smiles>c1cnc2c(c1)Sc1nc3ccccc3nc1N2</smiles>

1<smiles>Cc1cc2nc3c(nc2cc1C)Sc1ccccc1CN3</smiles>

2<smiles>Clc1cc2nc3c(nc2cc1Cl)Sc1ccccc1CN3</smiles><smiles>ClC(Cl)(Cl)c1nc(C(Cl)(Cl)Cl)nc(C(Cl)(Cl)Cl)n1</smiles>

$\mathrm{Tz}$

SCHEME 4

of radical cations generated by radiolysis. The positive charge was transferred to the solute molecule with a lower ionization potential (in this case the dye) to give the corresponding radical cation (reactions (5)-(7)):

$$
\begin{gathered}
\mathrm{BMIM}^{+}, \mathrm{PF}_{6}^{-} \longrightarrow \mathrm{BMIM}^{2+\bullet}, \mathrm{PF}_{6}{ }^{\bullet}, \mathrm{e}^{-}, \\
\mathrm{CH}_{2} \mathrm{Cl}_{2} \longrightarrow \mathrm{CH}_{2} \mathrm{Cl}_{2}^{\bullet+}+\mathrm{e}^{-}, \\
\mathrm{CH}_{2} \mathrm{Cl}_{2}+\mathrm{e}^{-} \longrightarrow \mathrm{CH}_{2} \mathrm{Cl}^{\bullet}+\mathrm{Cl}^{-}, \\
\mathrm{CH}_{2} \mathrm{Cl}_{2}^{\bullet+}+\text { Dye } \longrightarrow \mathrm{CH}_{2} \mathrm{Cl}_{2}+\mathrm{Dye}^{\bullet+}, \\
\mathrm{BMIM}^{2+\bullet}+\text { Dye } \longrightarrow \mathrm{BMIM}^{+}+\mathrm{Dye}^{\bullet+}, \\
\mathrm{PF}_{6}{ }^{\bullet}+\text { Dye } \longrightarrow \mathrm{PF}_{6}{ }^{-}+\mathrm{Dye}^{\bullet+} .
\end{gathered}
$$

Additionally, upon thermal annealing of the glassy samples chloromethyl radicals reacted with $\mathrm{O}_{2}$, forming the oxidizing peroxyl radicals (reaction (8)), which subsequently oxidized the dye (reaction (9)):

$$
\begin{gathered}
\mathrm{CH}_{2} \mathrm{Cl}^{\bullet}+\mathrm{O}_{2} \longrightarrow \mathrm{CH}_{2} \mathrm{ClO}_{2}{ }^{-}, \\
\mathrm{CH}_{2} \mathrm{ClO}_{2}{ }^{\bullet}+\text { Dye } \longrightarrow \mathrm{CH}_{2} \mathrm{ClO}_{2}^{-}+\mathrm{Dye}^{\bullet+} .
\end{gathered}
$$

\section{Results and Discussion}

3.1. Sensitized Free Radical Photopolymerization. The efficiency of benzothiazine dye derivatives of $12 \mathrm{H}$-quinoxalino$[2,3-b][1,4]$-benzothiazine $(\mathbf{1}-\mathbf{3})$ in combination with $\mathbf{T z}$ as photoinitiating systems for the free radical polymerization of TMPTA was evaluated. It is well known, that the most efficient dyeing photoinitiators are the photoredox pair in which electron transfer occurs with the participation of the excited triplet states $[4,6,7,15]$. Therefore, dyes 1-3 were selected as efficient oxidizable sensitizers with a high
TABLe 1: Photophysical and electrochemical properties of studied dyes.

\begin{tabular}{lccc}
\hline Dye & $\lambda_{\max }{ }^{\mathrm{a}}(\mathrm{nm})$ & $E_{\text {ox }}{ }^{\mathrm{b}}(\mathrm{V})$ & $E^{00 \mathrm{c}}\left(\mathrm{kJ} \mathrm{mol}^{-1}\right)$ \\
\hline $\mathbf{1}$ & 425 & 0.97 & 260 \\
$\mathbf{2}$ & 424 & 0.79 & 259 \\
$\mathbf{3}$ & 442 & 0.90 & 253 \\
\hline
\end{tabular}

quantum yield of triplet state generation $(\sim 0.8[7])$. The spectroscopic and electrochemical properties of these dyes are presented in Table 1. The benzothiazine dyes absorbed light at higher wavelengths than $\mathbf{T z}(304 \mathrm{~nm})$; therefore the band-pass filters were used to irradiate the dye alone in photopolymerization experiments.

The efficiency of the polymerization initiated by the dye/Tz systems was measured indirectly from the reaction's heat flow during irradiation. The overall polymerization results are summarized in Table 2 .

The calculated polymerization rate of TMPTA (Table 2) indicated that the efficiency of polymerization strongly depended upon the structure of the dye employed. It was apparent that dye $\mathbf{1}$ significantly accelerated triacrylate photopolymerization in comparison with dyes $\mathbf{2}$ and 3. Free radical polymerization initiated by the tested photoredox pairs showed a significant inhibition time (Table 2). This effect should be related to the molecular oxygen dissolved in the composition. The oxygen both quenched the triplet state of the dye and reacted with the radical species generated by the dye/Tz systems. After consumption of the oxygen, the initiating radicals reacted with the monomer. As seen in Table 2, the most efficient photoredox pair, $\mathbf{1 / T z}$, had the shortest inhibition time. 
TABLE 2: Rate of photopolymerization, inhibition time, and thermodynamic parameters of studied photoredox pairs.

\begin{tabular}{lccc}
\hline Dye & $R_{p}{ }^{\mathrm{a}}\left(\mu \mathrm{mol} \mathrm{s}^{-1}\right)$ & Inhibition time ${ }^{\mathrm{a}}(\mathrm{s})$ & $-\Delta G_{\text {et }}\left(\mathrm{kJ} \mathrm{mol}^{-1}\right)$ \\
\hline $\mathbf{1}$ & 42.8 & 26 & 32.0 \\
$\mathbf{2}$ & 11.6 & 41 & 48.5 \\
$\mathbf{3}$ & 9.6 & 68 & 31.8 \\
\hline
\end{tabular}

${ }^{\mathrm{a}}[$ Dye $]=0.1 \mathrm{mM},[\mathrm{Tz}]=10 \mathrm{mM}$.

It is well-known [26] that for polymerization initiated via intermolecular electron transfer process, the $R_{p}$ can be described by the followings:

$$
\ln R_{p}=A-\frac{\lambda\left(1+\Delta G_{\mathrm{et}} / \lambda\right)^{2}}{4 R T},
$$

where $A$ is a constant, which depends on the intensity of absorbed light $\left(I_{a}\right)$, quantum yield of triplet state formation $\left(\Phi_{T}\right)$, the rate constants of polymerization $\left(k_{p}\right)$ and chain termination steps $\left(k_{t}\right)$, and the concentration of monomer and coinitiators. The examined dyes had the same value of singlet oxygen generation $(\sim 0.8[7])$ and one could conclude that their $\Phi_{T}$ values are also comparable. In the present study, the free energy change of electron transfer $\left(\Delta G_{\text {et }}\right)$ was calculated from the Rehm-Weller equation as follows [27]:

$$
\begin{aligned}
\Delta G_{\text {et }}\left(\mathrm{kJ} \mathrm{mol}^{-1}\right)= & 97\left[E_{\text {ox }}\left(\frac{D}{D^{\bullet+}}\right)-E_{\text {red }}\left(\frac{A^{\bullet-}}{A}\right)\right] \\
& -E^{00}(D)-\frac{Z_{1} Z_{2}}{\varepsilon r_{12}},
\end{aligned}
$$

In this equation, $E_{\mathrm{ox}}\left(D / D^{\bullet+}\right)$ and $E^{00}(D)$ are the oxidation potential of the dye and the singlet excited state energy of the dye, respectively. Both parameters are given in Table 1. $E_{\text {red }}$ $\left(A^{\bullet-} / A\right)$ is the reduction potential of $\mathbf{T z}(-1.0 \mathrm{~V}$ [17]). The last term represents the Coulombic energy necessary to form an ion pair with charges $Z_{1}$ and $Z_{2}$ in a medium of dielectric constant $\varepsilon$ for a distance $r_{12}$. This factor is often ignored, taking into account the overall value of $\Delta G_{\text {et }}$. The calculated thermodynamic parameters listed in Table 2 indicate that all combinations of the benzothiazine dye/Tz systems possessed a strong driving force $\left(-\Delta G_{\mathrm{et}}>31 \mathrm{~kJ} \mathrm{~mol}^{-1}\right)$ upon exposure to light. The photoelectron transfer process occurred easily through the excited state. The detailed revision of the experimental data presented in Table 2 reveal that the photosystem $2 / \mathrm{Tz}$ with a high driving force for electron transfer $\left(-\Delta G_{\text {et }}\right)$ had moderate $R_{p}$ and inhibition time in comparison with the other studied dyes. The same effects have been observed for photopolymerization initiated by the other photoredox systems $[8,20,26]$.

3.2. Photodarkening Mechanism. During photopolymerization of the triacrylate monomer, the studied sensitizer does not really photobleach but photodarkens. An explanation of this phenomenon demands the identification of the products formed during photolysis. Therefore, the photooxidation mechanism of compound $\mathbf{1}$ was studied in detail. Because the proton of the nitrogen heteroatom in 1 can participate in the deprotonation reaction following the oxidation

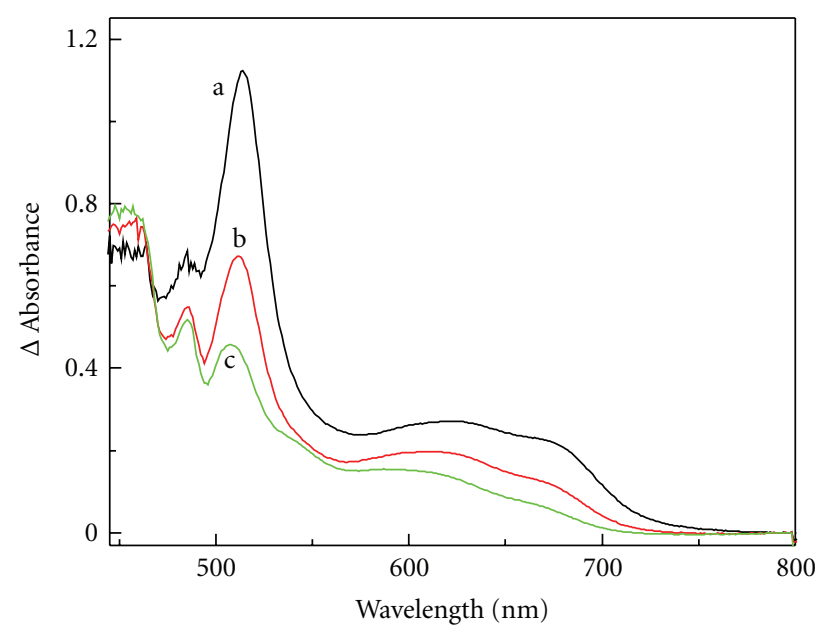

(A)

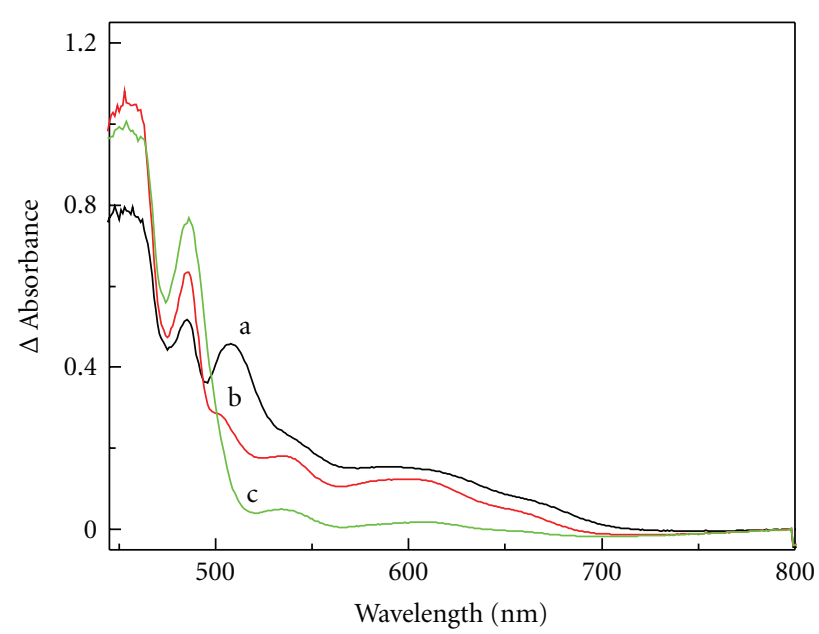

(B)

FIGURE 1: Electronic absorption spectra obtained on oxidation of 1 (saturated solution, $<0.01 \mathrm{M}$ ) embedded in a $\mathrm{BMIM}^{+} \mathrm{PF}_{6}{ }^{-}: \mathrm{CH}_{2} \mathrm{Cl}_{2}$ ( $1: 1$ ) matrix. (A) spectra were collected after radiolysis at $77 \mathrm{~K}$ (a) and after annealing of the matrix at $140 \mathrm{~K}$ for $5 \mathrm{~min}$ (b) and for $15 \mathrm{~min}$ (c). (B) After annealing at $140 \mathrm{~K}$ for $25 \mathrm{~min}$ (a) and at $150 \mathrm{~K}$ for $10 \mathrm{~min}$ (b) and $20 \mathrm{~min}$ (c). The sample was $2 \mathrm{~mm}$ thick and received a radiation dose of $7.2 \mathrm{kGy}$.

of benzothiazine, the pulse radiolysis of low temperature matrices was applied to the spectroscopic characterization of its radical cation and neutral radical. The electronic absorption spectrum of the radical cation $1^{\cdot+}$ obtained by low-temperature methodology is presented in Figure 1(A). The spectrum consisted of a strong absorption band at $514 \mathrm{~nm}$ and two smaller peaks at longer wavelengths of $620 \mathrm{~nm}$ and $675 \mathrm{~nm}$. These bands decayed upon limited warming of the matrix (Figure 1(B)). The decrease of the absorption of $1^{\cdot+}$ was accompanied by an increase of the absorption band at $485 \mathrm{~nm}$. This product was stable at room temperature.

Radical cations are more acidic than their neutral precursors and some of them are even superacids $[28,29]$. 


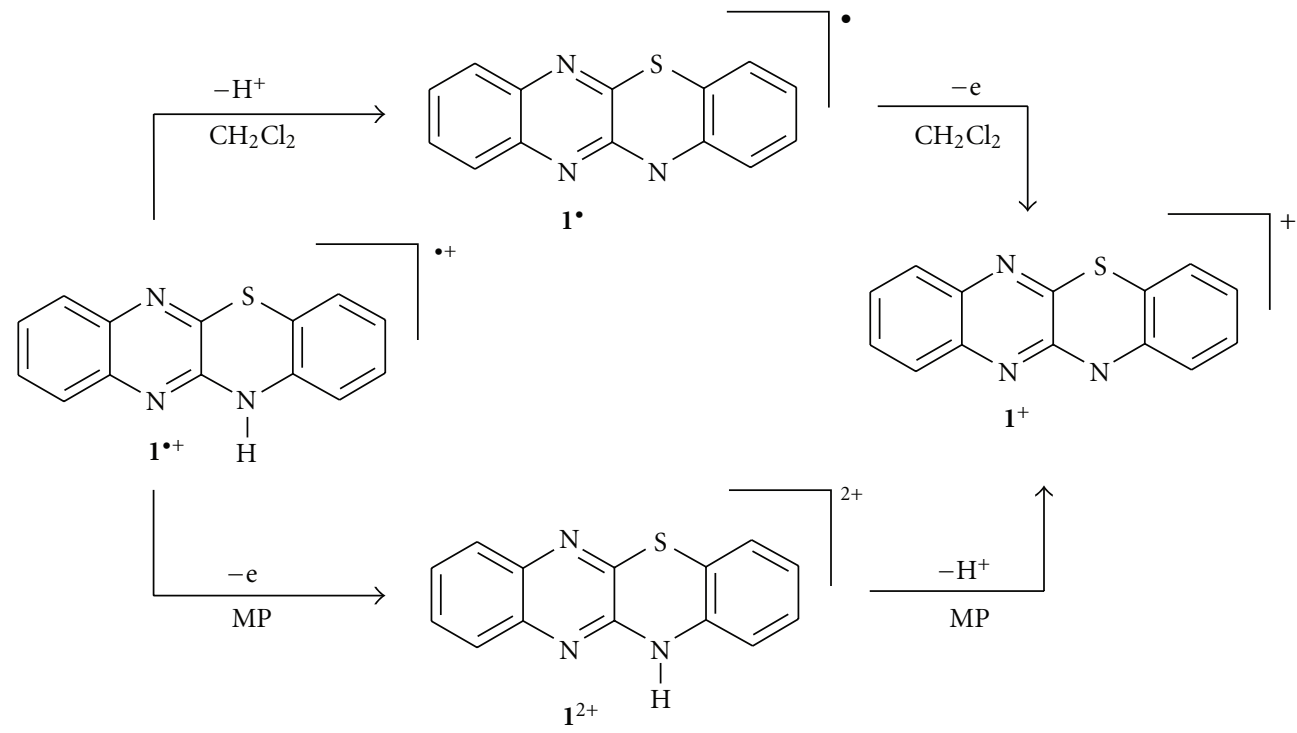

SCHeme 5

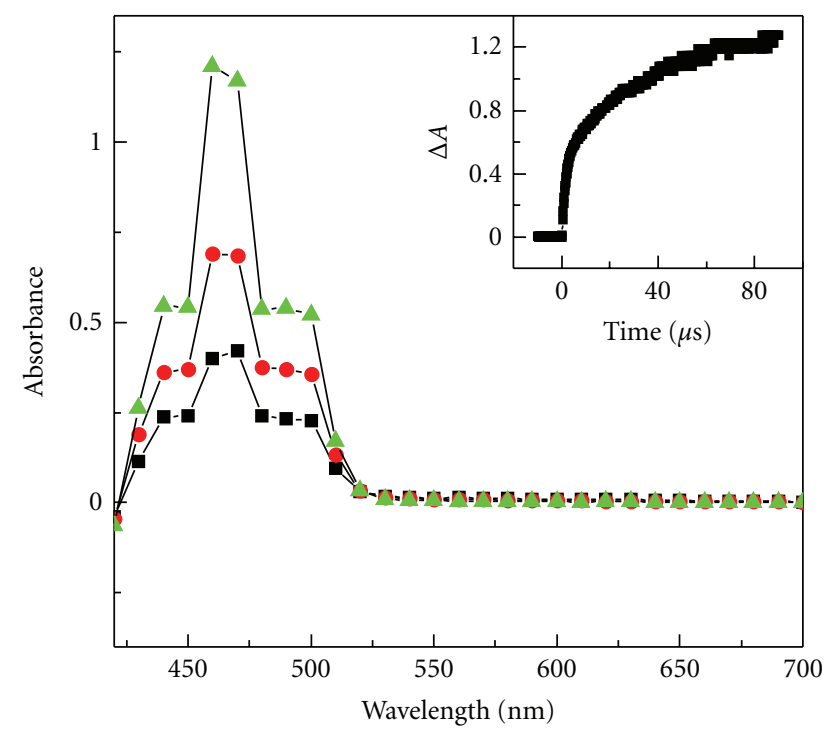

FIGURE 2: Transient absorption spectrum obtained by pulse radiolysis of $1(0.2 \mathrm{mM})$ in an oxygen saturated $\mathrm{CH}_{2} \mathrm{Cl}_{2}$ solution. The spectrum was collected at (black square) $2 \mu \mathrm{s}$, (red circle) $10 \mu \mathrm{s}$, and (green triangle) $80 \mu$ s after an electron pulse. Inset: change in absorbance at $460 \mathrm{~nm}$. The sample was $1 \mathrm{~cm}$ thick and received a radiation dose of $66 \mathrm{~Gy}$.

Therefore they readily undergo deprotonation. Under matrix conditions the radical cation deprotonation can only start upon matrix softening. Therefore, one can conclude that radical cation $1^{\circ+}$ undergoes deprotonation into the neutral radical $1^{\bullet}$ (Scheme 5) on annealing of the matrix. The generation of the amine radical was more apparent in pulse radiolysis in $\mathrm{CH}_{2} \mathrm{Cl}_{2}$ at room temperature. Transient absorption spectra recorded under oxygen conditions are presented in Figure 2.

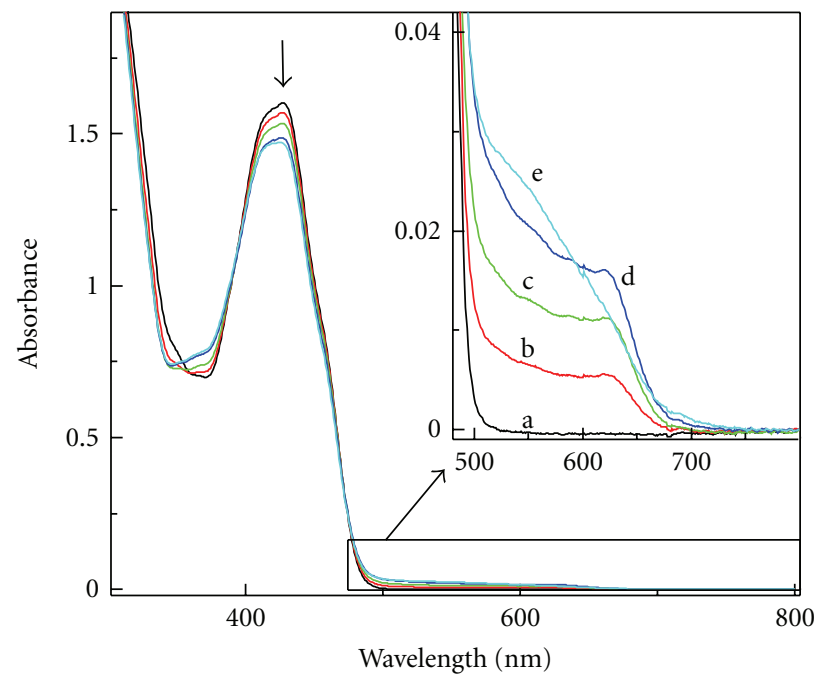

FIGURE 3: Electronic absorption spectra obtained during photolysis of the dye $1(0.1 \mathrm{mM})$ and $\mathrm{Tz}(1 \mathrm{mM})$ in MP in the presence of air. Irradiation intensity $2 \times 10^{16}$ quant s$^{-1}$. The spectrum recorded before (a) $0 \mathrm{~s}$ and after (b) $5 \mathrm{~s}$, (c) $10 \mathrm{~s}$, (d) $15 \mathrm{~s}$, and (e) $20 \mathrm{~s}$ irradiation.

In such experimental conditions, a product with absorption bands at $440 \mathrm{~nm}, 460 \mathrm{~nm}$, and $490 \mathrm{~nm}$ were observed. The bands were assigned to neutral radical $\mathbf{1}^{\circ}$. In an oxygensaturated solution, the ${ }^{\bullet} \mathrm{CH}_{2} \mathrm{Cl}$ radical reacted rapidly with $\mathrm{O}_{2}$ to form the peroxyl radical, which oxidized dye 1 to the radical cation $1^{\bullet+}$ that undergoes deprotonation into the neutral radical $1^{\circ}$. Similar deprotonation of the radical cation of phenothiazine in n-butyl chloride was observed [30]. Therefore, the direct oxidation of compound 1 by the trichloromethylperoxyl radical to its radical cation was observed in a 2-PrOH-water solution with $0.1 \mathrm{M}$ of $\mathrm{HClO}_{4}$ 


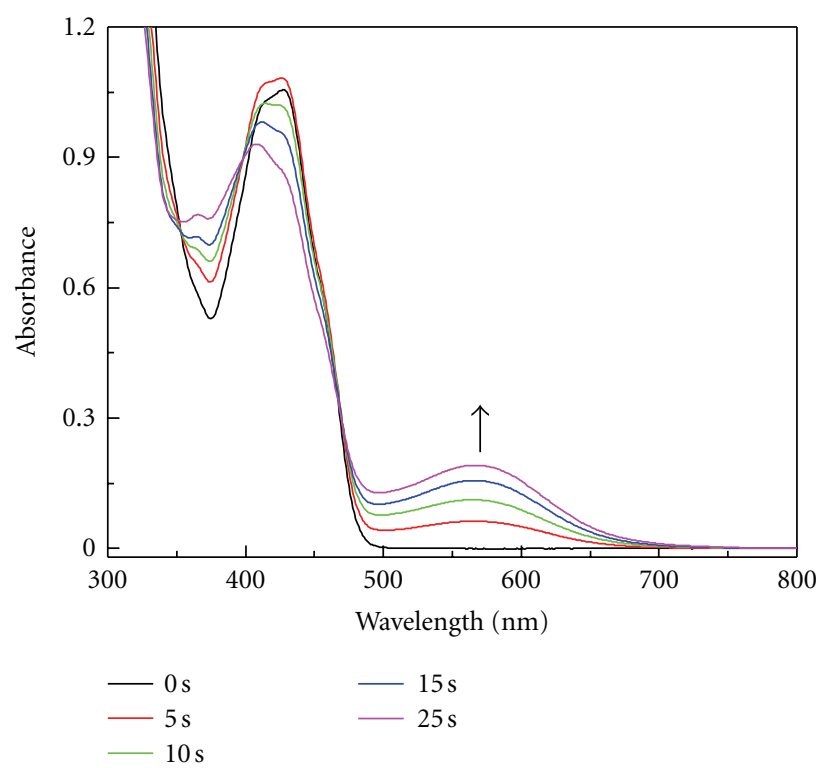

(a)

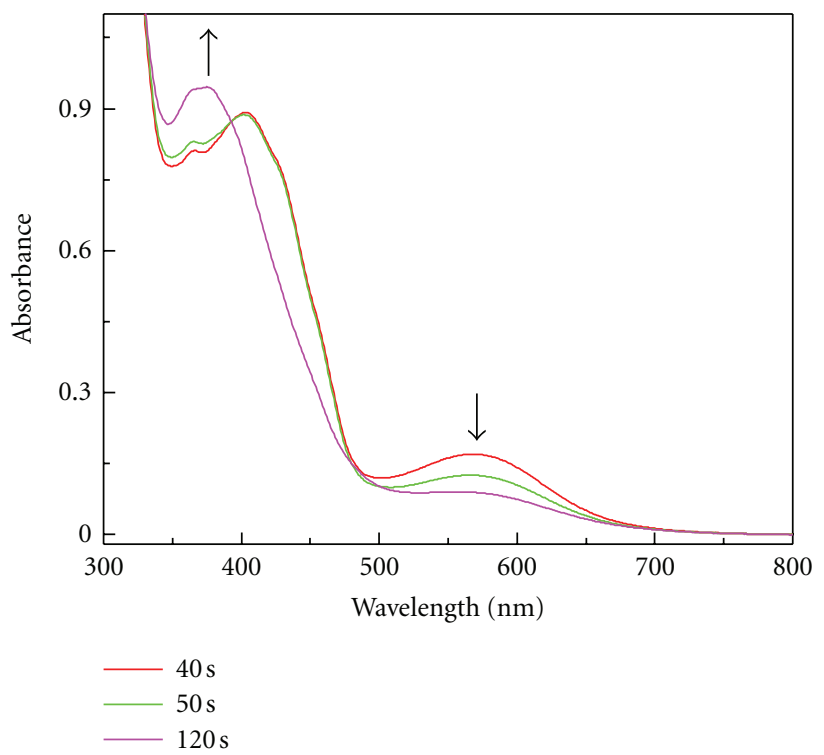

(b)

FIGURE 4: Electronic absorption spectra obtained during photolysis of the dye $\mathbf{1}(0.1 \mathrm{mM})$ and $\mathbf{T z}(1 \mathrm{mM})$ in $\mathrm{MP}$ solution containing $0.37 \mathrm{M}$ TMPTA in the presence of air. Irradiation intensity $6 \times 10^{16}$ quant $\mathrm{s}^{-1}$.

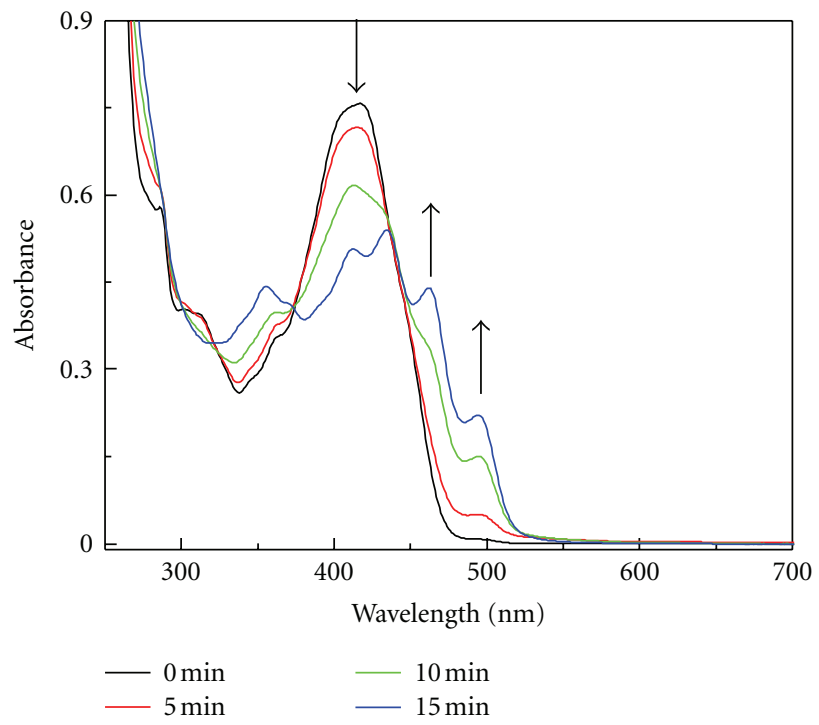

(a)

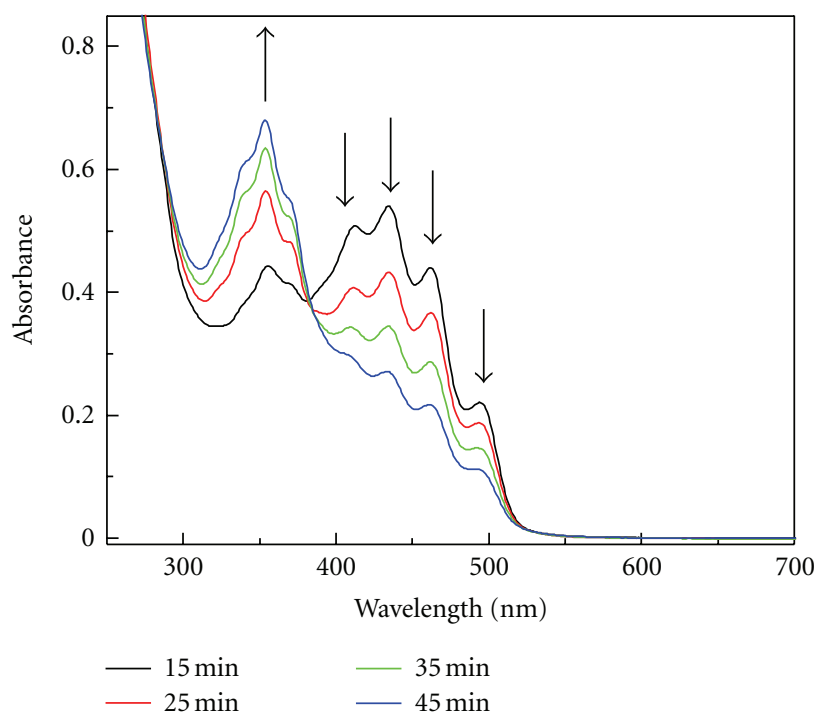

(b)

FIGURE 5: Electronic absorption spectra obtained during photolysis of dye $\mathbf{1}(0.1 \mathrm{mM})$ in $\mathrm{CH}_{2} \mathrm{Cl}_{2}$ in the presence of air. Irradiation intensity $6 \times 10^{16}$ quant s$^{-1}$.

at room temperature. The pKa of compound $\mathbf{1}$ in the 2 $\mathrm{PrOH}$-water solution was estimated to be approximately 0.4 . The transient absorption spectrum recorded in the acidic condition consisted of a strong absorption band at $500 \mathrm{~nm}$ and two smaller peaks at longer wavelengths of 550 and $600 \mathrm{~nm}$. A similar absorption was obtained in the cryogenic matrix (see Figure 1(a)). Thus, the formation of $\mathbf{1}^{\bullet+}$ was followed at $500 \mathrm{~nm}$. The observed rate of oxidation increased linearly with dye concentration $(0.56$ to $0.96 \mathrm{mM})$. The plot of $k_{\text {obs }}$ versus concentration of the dye was used to determine the second order rate constant ${ }^{2} k=(2.18 \pm 0.08) \times$ $10^{7} \mathrm{M}^{-1} \mathrm{~s}^{-1}$.

After spectroscopic characterization of $\mathbf{1}^{\bullet+}$ and $\mathbf{1}^{\bullet}$, the photolysis of benzothiazine dye $\mathbf{1}$ in composition with $\mathrm{Tz}$ was examined in MP. The electronic spectra recorded in MP showed the characteristic broad absorption band at $625 \mathrm{~nm}$ (Figure 3), which was assigned to $\mathbf{1}^{\bullet+}$.

The same effect was observed during irradiation of the 1/Tz photoredox pair in MP containing $0.37 \mathrm{M}$ TMPTA. Extending the irradiation time to $30 \mathrm{~s}$ caused an increase 
of the new band at $560 \mathrm{~nm}$ but the absorption bands of radical $\mathbf{1}^{\bullet}$ were not detected. When the photolysis was carried out with higher irradiation intensity $(6 \times$ $10^{16}$ quant s$^{-1}$ ) the broad absorption band at $560 \mathrm{~nm}$ was observed (Figure 4(a)).

Moreover, extending the irradiation time to $50-120 \mathrm{~s}$ caused a decrease in the absorption bands at $560 \mathrm{~nm}$. Decay of the absorption at $560 \mathrm{~nm}$ is accompanied by the growth of a band near $358 \mathrm{~nm}$. A similar absorption spectrum was observed for the dication of $12 \mathrm{H}$-benzo [b]phenothiazine (4) [31] which is converted into cation by the lost of the proton. Therefore, one can conclude that radical cation $1^{\circ+}$ underwent a one-electron oxidation to the dication $\mathbf{1}^{2+}$ (Scheme 5). Then, $\mathbf{1}^{2+}$ underwent deprotonation to cation $\mathbf{1}^{+}$. The isosbestic point at $398 \mathrm{~nm}$ (Figure 4(b)) confirms such direct conversion.<smiles>c1ccc2c(c1)CNc1cc3ccccc3cc1S2</smiles>

4

For comparison the photolysis of dye $\mathbf{1}$ in $\mathrm{CH}_{2} \mathrm{Cl}_{2}$ was carried out. In this steady state photolysis dichloromethane was used as an electron acceptor. Electronic absorption spectrum (Figure 5) recorded after 15 minutes of irradiation showed the characteristic absorption bands at $412 \mathrm{~nm}$, $435 \mathrm{~nm}, 462 \mathrm{~nm}$, and $494 \mathrm{~nm}$ similar to the spectrum obtained during radiolysis (see Figure 2).

Thus, the product formed during photolysis in $\mathrm{CH}_{2} \mathrm{Cl}_{2}$ is neutral radical $1^{\circ}$. The elongation of irradiation time to 50 min caused the decrease the absorption of $1^{\circ}$. While the $1^{\bullet}$ disappears, the band at $353 \mathrm{~nm}$ increases. Therefore, we assigned this new band to $\mathbf{1}^{+}$cation (Scheme 5), which might be formed during oxidation of $1^{\bullet}$ by $\mathrm{CH}_{2} \mathrm{Cl}_{2}$ or peroxyl radical $\mathrm{CH}_{2} \mathrm{ClO}_{2}{ }^{\circ}$.

Based on the presented above results, one can assume that in MP, $\mathbf{1}^{\mathbf{}+}$ underwent a one-electron oxidation to the dication $\mathbf{1}^{2+}$ (Scheme 5). It is concluded that the photodarkening of the polymer was caused by the radical cation or dication of the studied dyes and not the neutral radical. Such behavior is normally unwanted, particularly in composites, because it diminishes the curing of deeper layers of resin. However, in some situations, such as stereolithography, photodarkening may be an advantage, since it reduces the penetration of radiation below the top photocuring layer and allows higher pattern resolution.

\section{Conclusions}

Novel photoinitiator systems constructed with dye derivatives of $12 \mathrm{H}$-quinoxalino-[2,3-b][1,4]-benzothiazine (1-3) and 2,4,6-tris(trichloromethyl)-1,3,5-triazine ( $\mathbf{T z}$ ) are found to be effective initiation systems for free radical polymerization of TMPTA using VIS light. Photosensitization occurs through electron transfer, which was confirmed by the observation of a radical cation of the dyes studied during photolysis. The radical cation formed after electron transfer between benzothiazine dye $\mathbf{1}$ and $\mathrm{Tz}$ in MP underwent oneelectron oxidation to yield the dication $\mathbf{1}^{2+}$. The formation of the neutral radical $\mathbf{1}^{\bullet}$ was observed during radiolysis and photolysis of benzothiazine dye 1 in $\mathrm{CH}_{2} \mathrm{Cl}_{2}$. The cation $1^{+}$was formed as results of two reactions: deprotonation of dication $\mathbf{1}^{2+}$ or oxidation of neutral radical $1^{\circ}$. The photodarkening of the polymers was caused by the radical cation or dication from the sensitizers.

\section{Acknowledgments}

This work was supported by the Polish Ministry of Science and Higher Education (Project no. N N205 1454 33).

\section{References}

[1] C. Lowe, G. Webster, S. Kessel, and I. McDonald, Chemistry and Technology of UV and EB Formulation for Coatings, Inks and Paints, vol. 4 of Surface Coating Technology, Wiley, London, UK, 1996.

[2] P. K. T. Oldring, Chemistry and Technology of UV and EB Formulation for Coatings, Inks and Paints, vol. 5 of Speciality Finishes, Wiley, Sita Techn. Ltd., London, UK, 1997.

[3] R. Podsiadły, "Photoreaction and photopolymerization studies on fluoflavin dye-pyridinium salt systems," Journal of Photochemistry and Photobiology A, vol. 198, no. 1, pp. 60-68, 2008.

[4] J. Kolińska, R. Podsiadły, and J. Sokołowska, "Naphthoylenebenzimidazolone sensitisers for photo-oxidisable free radical polymerisation with the aid of pyridinium salts," Coloration Technology, vol. 124, no. 6, pp. 341-347, 2008.

[5] R. Podsiadły, A. M. Szymczak, and K. Podemska, "The synthesis of novel, visible-wavelength, oxidizable polymerization sensitizers based on the 8-halogeno-5,12-dihydroquinoxalino[2,3-b] quinoxaline skeleton," Dyes and Pigments, vol. 82, no. 3, pp. 365-371, 2009.

[6] R. Podsiadły, "The synthesis of novel, visible-wavelength oxidizable polymerization sensitizers based on the 5,12dihydroquinoxalino[2,3-b] pyridopyrazine skeleton," Dyes and Pigments, vol. 80, no. 1, pp. 86-92, 2009.

[7] R. Podsiadły, "Synthesis and photochemical reaction of novel, visible-wavelength oxidizable polymerization sensitizer based on the $12 \mathrm{H}$-quinoxalino[2,3-b][1,4]benzothiazine skeleton," Journal of Photochemistry and Photobiology A, vol. 202, no. 2-3, pp. 115-121, 2009.

[8] R. Podsiadły, J. Sokołowska, and J. Stoczkiewicz, "Styryl dyes as new photoinitiators for free radical polymerization," Dyes and Pigments, vol. 77, no. 3, pp. 510-514, 2008.

[9] R. Podsiadły, J. Kolińska, and J. Sokołowska, "Study of free radical polymerisation with dye photoinitiators containing a naphthoylenebenzimidazolone skeleton," Coloration Technology, vol. 124, no. 2, pp. 79-85, 2008.

[10] B. Przyjazna, Z. Kucybała, and J. Pạczkowski, "Development of new dyeing photoinitiators based on $6 \mathrm{H}$-indolo $[2,3-b]$ quinoxaline skeleton," Polymer, vol. 45, no. 8, pp. 2559-2566, 2004.

[11] M. V. Encinas, A. M. Rufs, S. G. Bertolotti, and C. M. Previtali, "Xanthene dyes/amine as photoinitiators of radical polymerization: a comparative and photochemical study in aqueous medium," Polymer, vol. 50, no. 13, pp. 2762-2767, 2009. 
[12] X. Wan, Y. Zhao, J. Xue, F. Wu, and X. Fang, "Water-soluble benzylidene cyclopentanone dye for two-photon photopolymerization," Journal of Photochemistry and Photobiology A, vol. 202, no. 1, pp. 74-79, 2009.

[13] I. Fitilis, M. Fakis, I. Polyzos, V. Giannetas, and P. Persephonis, "Two-photon polymerization of a diacrylate using fluorene photoinitiators-sensitizers," Journal of Photochemistry and Photobiology A, vol. 215, no. 1, pp. 25-30, 2010.

[14] J. Kabatc, "Multicationic monomethine dyes as sensitizers in two- and three-component photoinitiating systems for multiacrylate monomers," Journal of Photochemistry and Photobiology A, vol. 214, no. 1, pp. 74-85, 2010.

[15] J. Kabatc and J. Paczkowski, "Monomeric asymmetric twoand three-cationic monomethine cyanine dyes as novel photoinitiators for free-radical polymerization," Dyes and Pigments, vol. 86, no. 2, pp. 133-142, 2010.

[16] O. I. Tarzi, X. Allonas, C. Ley, and J. P. Fouassier, "Pyrromethene derivatives in three-component photoinitiating systems for free radical photopolymerization," Journal of Polymer Science A, vol. 48, no. 12, pp. 2594-2603, 2010.

[17] C. Grotzinger, D. Burget, P. Jacques, and J. P. Fouassier, "Photopolymerization reactions initiated by a visible light photoinitiating system: dye/amine/ bis(trichloromethyl)substituted-1,3,5-triazine," Macromolecular Chemistry and Physics, vol. 202, no. 18, pp. 3513-3522, 2001.

[18] T. Karatsu, M. Yanai, S. Yagai, J. Mizukami, T. Urano, and A. Kitamura, "Evaluation of sensitizing ability of barbituratefunctionalized non-ionic cyanine dyes; application for photoinduced radical generation system initiated by near IR light," Journal of Photochemistry and Photobiology A, vol. 170, no. 2, pp. 123-129, 2005.

[19] T. Urano, T. Nagao, A. Takada, and H. Itoh, "Photosensitization mechanisms in photopolymer coating film containing photoinitiators sensitized by aminochalcone-type dye for computer-to-photopolymer plate," Polymers for Advanced Technologies, vol. 10, no. 4, pp. 244-250, 1999.

[20] R. Podsiadły and J. Sokołowska, "Synthesis of novel oxidizable polymerization sensitizers based on the dithiinoquinoxaline skeleton," Dyes and Pigments, vol. 92, no. 3, pp. 1300-1307, 2012.

[21] J. G. Huddleston, H. D. Willauer, R. P. Swatloski, A. E. Visser, and R. D. Rogers, "Room temperature ionic liquids as novel media for "clean" liquid-liquid extraction," Chemical Communications, no. 16, pp. 1765-1766, 1998.

[22] W. B. Leighton and G. S. Forbes, "Precision actinometry with uranyl oxalate," Journal of the American Chemical Society, vol. 52, no. 8, pp. 3139-3152, 1930.

[23] D. Avci, J. Nobles, and L. J. Mathias, "Synthesis and photopolymerization kinetics of new flexible diacrylate and dimethacrylate crosslinkers based on C18 diacid," Polymer, vol. 44, no. 4, pp. 963-968, 2003.

[24] S. Karolczak, K. Hodyr, R. Łubis, and J. Kroh, "Pulse radiolysis system based on ELU-6E LINAC," Journal of Radioanalytical and Nuclear Chemistry Articles, vol. 101, no. 2, pp. 177-188, 1986.

[25] S. Karolczak, K. Hodyr, and M. Polowinski, "Pulse radiolysis system based on ELU-6E LINAC - II. Development and upgrading the system," Radiation Physics and Chemistry, vol. 39, no. 1, pp. 1-5, 1992.

[26] J. Pączkowski and Z. Kucybała, "Generalization of the kinetic scheme for a dye-photosensitized free-radical polymerization initiating system via an intermolecular electron-transfer process. Application of marcus theory," Macromolecules, vol. 28, no. 1, pp. 269-273, 1995.

[27] D. Rehm and A. Weller, "Kinetics of fluorescence quenching by electron and H-atom transfer," Israel Journal of Chemistry, vol. 8, no. 2, pp. 259-271, 1970.

[28] T. Bally, "Properties in condensed phases," in Radical Ionic Systems, A. Lund and M. Shiotani, Eds., pp. 3-54, Kluwer Academic, Dordrecht, The Netherlands, 1991.

[29] J. Gębicki and A. Marcinek, "Radical Ions: generation, characterization and reactions," in General Aspects of the Chemistry of Radicals, Z. B. Alfassi, Ed., pp. 175-208, Wiley, Chichester, UK, 1999.

[30] O. Brede, A. Maroz, R. Hermann, and S. Naumov, "Ionization of cyclic aromatic amines by free electron transfer: products are governed by molecule flexibility," Journal of Physical Chemistry A, vol. 109, no. 36, pp. 8081-8087, 2005.

[31] N. Urasaki, S. Yoshida, T. Ogawa, K. Kozawa, and T. Uchida, "Oxidation potential and absorption spectra of phenothiazine derivatives I. Benzophenothiazine and triphenodithiazine," Bulletin of the Chemical Society of Japan, vol. 67, no. 8, pp. 2024-2030, 1994. 


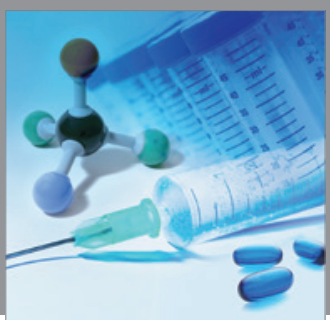

International Journal of

Medicinal Chemistry

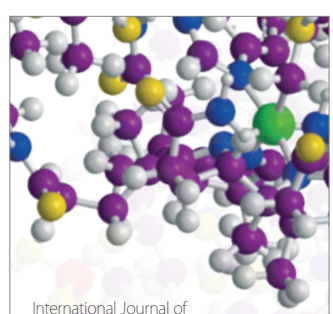

Carbohydrate Chemistry

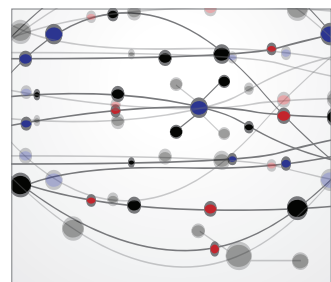

The Scientific World Journal
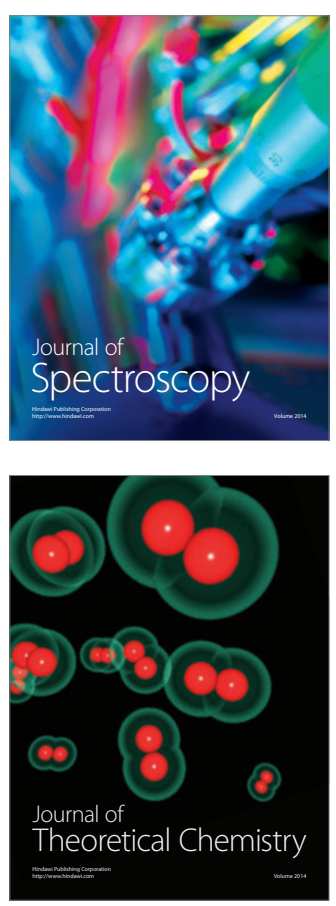
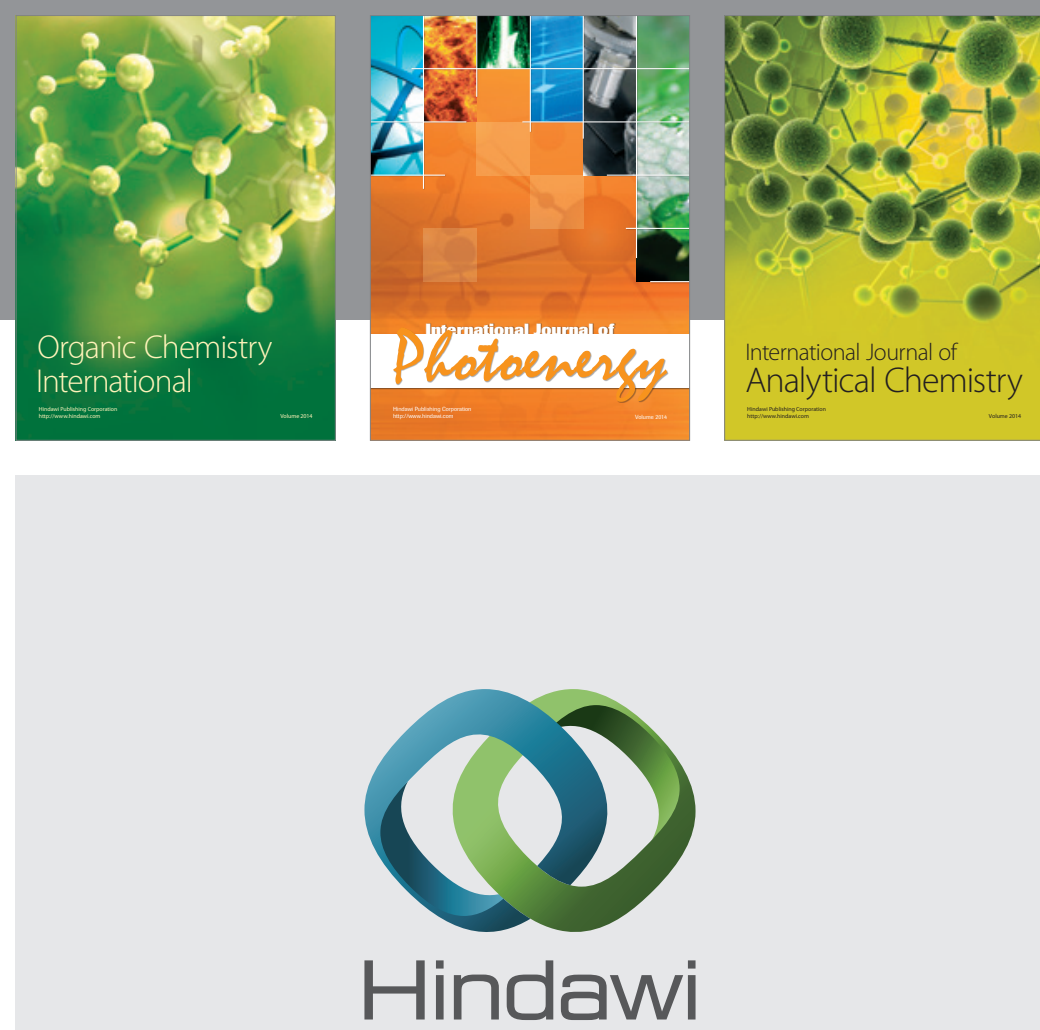

Submit your manuscripts at

http://www.hindawi.com
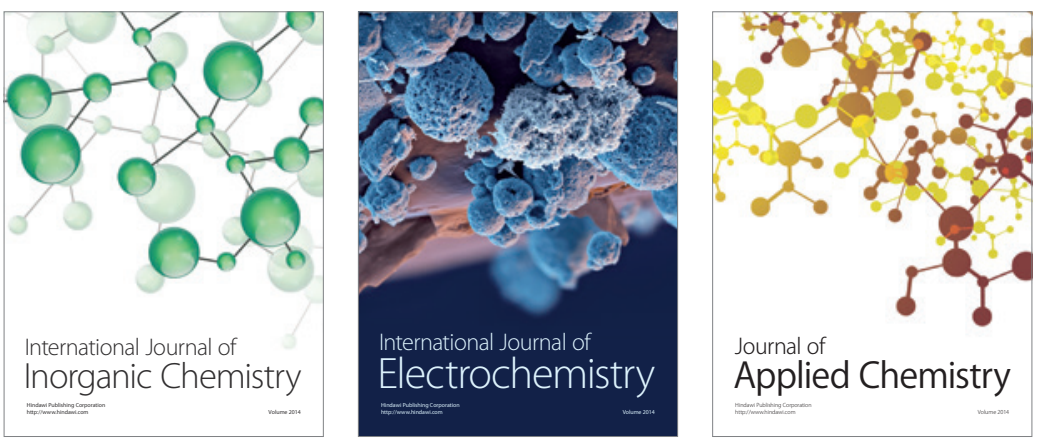

Journal of

Applied Chemistry
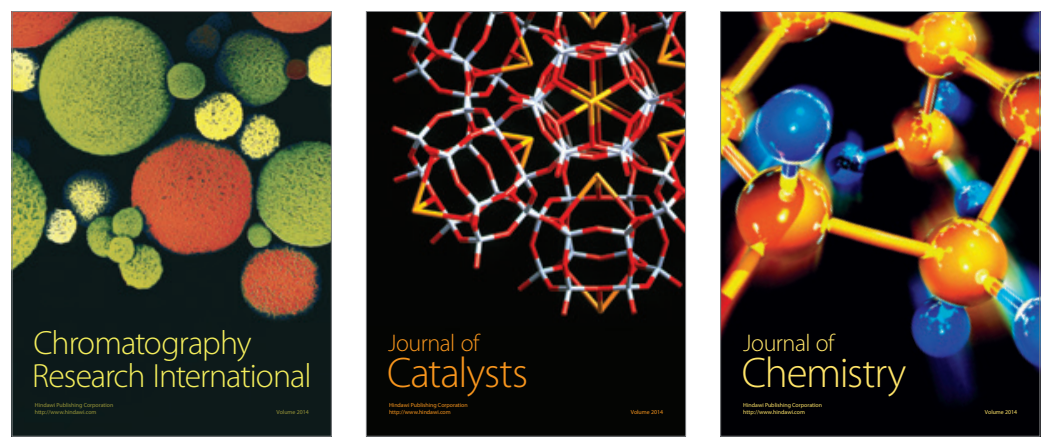
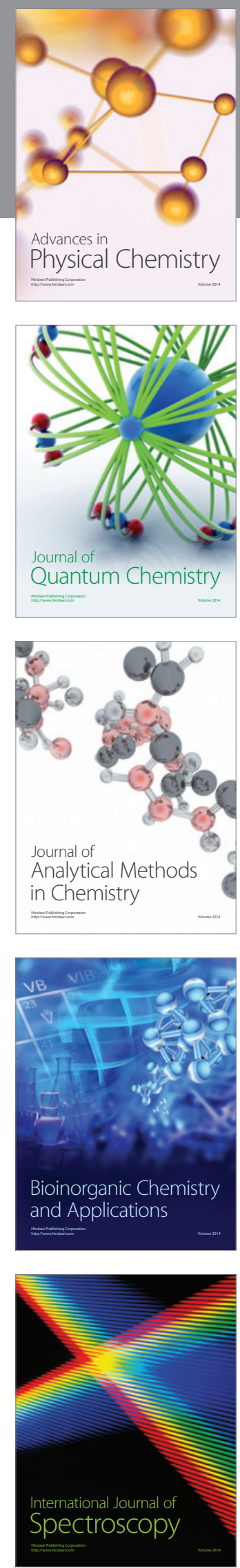